\title{
Models of Light and Properties of Light: Design and Assessment/Evaluation of a Simulation and Experimentation Supported Learning Environment
}

\author{
Nikolaos Voudoukis
}

\begin{abstract}
The purpose of this study is to propose a way for teaching models of light to upper secondary students. Even if the subject seems to be at the heart of modern physics, it is too difficult to be taught. This triggered us to design and apply a didactical approach, the evaluation of which seems to be beneficial for the instruction of this topic. Our instruction leads to better student's comprehension of the nature of light than traditional instruction. The didactical approach, which is a proposal for scientific to educational models transformation concerning light, was applied during the school year 2016-2017 to forty-seven (47) students - Experimental Group (EG) - of Upper Secondary Education in Athens. As control group (CG), teaching with the classic way, we have fifty (50) other students. In this paper, it is presented the main research. We describe the teaching method and laboratory experiments in this computer supported attempt. Results and some general conclusions from the statistical analysis of pre, post and final tests are also cited.
\end{abstract}

Index Terms-Models of Light; Dual Nature of Light; Properties of Light; Wave-Particle Duality; Didactical Approach; Teaching; Assessment; Evaluation; Education.

\section{INTRODUCTION - RATIONALE}

The aim of this study is: a) to investigate the ideas, comprehension and knowledge of upper secondary education students, who have been taught light with the classic way-traditional instruction, b) to propose a new didactical approach - scientific to educational models transformation, concerning light, for upper secondary education students, c) present the results and some general conclusions from the statistical analysis of post and final tests. This topic is chosen because the current curriculum for the upper secondary physics education in Greece includes references to contemporary scientific theories.

Main points for our didactical approach is: (i) to use experimentation for teaching models of light and highlight the dual nature of light (wave-particle duality), (ii) to compose - create electronic educational material, which will include simulations and visualizations as well as classical laboratory practices (laboratory experiments), so that students can select the most efficient model of light to explain a phenomenon, (iii) to compose - create a coursemodules with specific structure for the model of light, which is a way of teaching these models.

The results from the evaluation of the pre-research answers about light indicate that this topic is poorly

Published on June 30, 2018

N. Voudoukis is with National Technical University of Athens, Greece (e-mail: nvoudoukis@aspete.gr). understood by the majority of students, with the classic teaching way. Even if it seems to be at the heart of modern physics, it is too difficult to be taught. This fact triggered us to design and apply a didactical approach the evaluation of which seems, to be beneficial in the instruction of this topic.

\section{BACKGROUND, FRAMEWORK AND PURPOSE}

A researcher [1] argues that the wave-particle duality poses such a departure from the classical view - as well as a student's own life experience - that the utility in understanding it may be undermined by the misconceptions it leaves behind. Other researchers [2] focused on students' conceptions of the wave-particle duality by asking them how the results of diffraction experiments would differ depending on how various parameters in the experiment were altered. In contrast to Olsen [1] - who seems to see the teaching of the concept in a negative light altogether Vokos et al [2] have developed a tutorial, which attempts to address some of the shortcomings in students' conceptions of wave-particle duality by expanding their understanding of the wave nature of light and extending it into a wave model for particles. Another researcher [3] also describes a methodology that can be used to educate high-school aged students about quantum ideas. He attempts to use plausibility arguments to introduce students to the ideas of 1) quantization, 2) wave-particle duality, 3) non-locality, and 4) tunneling.

The studies concerning wave-particle duality [4]-[6] indicate the difficulty of the concept as this is a phenomenon that challenges our classical understanding of physics.

\section{EdUCATIONAL Aims}

The aim of this study is: a) to investigate the ideas that upper secondary education students have about light, b) to propose a new didactic approach / a model for teaching light - Scientific to Educational Models Transformation, concerning wave-particle duality of light, for upper secondary education students. Basic purpose for this effort is to use experiments as a proof and explain tool for properties and nature of light.

The main idea of the teaching method was the study of software, simulations and hands-on experiments for a phenomenon/property (reflection, refraction etc.) of light from students and the selection (after this study) of the appropriate model of light (wave, particle, both, neither) which explain the specific phenomenon [7]. 


\section{RESEARCH METHOdOLOGY - SAMPLES /EdUCATIONAL}

\section{TOOLS/INSTRUMENTS}

The didactical approach which developed consists of seven (7) units:

1. Propagation of light

2. Reflection of light

3. Interference - Diffraction of light

4. Refraction of light

5. Absorption of light

6. Analysis - Synthesis of light

7. Polarization of light

The intervention was performed on upper secondary students (17 years old) in Athens, Greece during the school year 2016-2017. The number of students participating in this study was forty-seven (47), divided into two classes-groups of twenty-four (24) and twenty-three (23) students. Each group was divided in eight (8) teams of three (3) students (there was one team of two students). For the assessment of the proposal they took post and final tests. These forty-seven students are the experimental group (EG). As control group (CG) we have fifty (50) other students divided into two classes-groups of twenty-five (25) students.

Teaching way: (i) For the EG a two hours' laboratory lesson for every one of the seven units mentioned above, which is our didactical proposal. Every team of three (3) students was given a computer with the software and a brochure (2-3 sheets) of instructions and questions. They navigated the software and executed the hands-on experiments following the instructions and answered the questions. At the end of the lesson, the students returned the completed brochure to the instructor-teacher who was present during the whole time.

For the educational approach of the different actions that take place in this paper, we suggest the educational model that includes the following steps:

1. Trigger of interest 2. Hypothesis expression 3 . Experiments 4. Formulation of conclusions and proposals recording 5. Generalisation - feedback - control [7].

The procedure of five steps supported by software. The developed software includes the above seven units. The software is an ICT-based interactive multimedia application created in the form of HTML pages, including simulations and visualizations. Moreover the application is a combination of software (simulations, visualizations, theory presentation) and experiments in laboratory (in the classical way). It includes the five aforementioned steps of the educational model.

(ii) For the CG a two hours' lesson for every one of the seven units mentioned above with the classic way-traditional instruction.

After one week a post-test questionnaire was used, consisting of ten (10) multiple choice questions, each with four (4) answers (a, b, c, d). Duration of answering the questions: twenty (20) minutes. One month later there was a final-test consisting of twenty (20) multiple choice questions with four (4) answers (a, b, c, d). Duration of answering the questions: forty (40) minutes. The final test was total for the seven units. SPSS was used for the statistical analysis.

\section{RESEARCH DESCRIPTION}

The application is a combination of software (simulations, visualizations, theory presentation) and experiments in laboratory (in the classical way). The platform used is an assembly of HTML files taking into consideration the five steps of the aforementioned educational model. The included visualizations and simulations were developed from us especially for this application-study in 3D Studio Max and Visual Basic 6.0 + OpenGL.

The course content has been divided into seven subject blocks-units. In every unit there are three (3) parts: wave model of light, particle model of light and the main subject of the unit (e.g. Reflection of light). The two parts, wave model of light and particle model of light are the same in every unit. This is for the purpose of the possibility of independent teaching of each subject-unit [7].

These subject units represent the basic unit of learning, and are organized in such a way as to present the fundamental content that the student must learn. From our point-of-view, this facilitates a progressive study of the contents when the student follows the logical, recommended order. The design of any application with such features is decidedly influenced by the teaching content which in our case is related to the nature of light (models of light). The media and formats for each concept being taught or example given (texts, photographs, graphics, animations, videos and narrations) were carefully selected in each case.

\section{RESULTS - FINDINGS}

Some characteristic results for a number of questions are presented at the following tables.

For the statistical analysis of students' answers we used SPSS10 (t-test), mentioned that the highest score-excellent for every test is ten (10).

TABLE I: POST-TEST MEAN SCORE PER UNIT FOR CONTROL GROUP (CG) AND EXPERIMENTAL GROUP (EG)

\begin{tabular}{|c|c|c|c|}
\hline & Unit & $\begin{array}{c}\text { Post-test of } \\
\text { Control } \\
\text { Group (CG) }\end{array}$ & $\begin{array}{l}\text { Post-test of } \\
\text { Experiment } \\
\text { al Group } \\
\text { (EG) }\end{array}$ \\
\hline 1 & Propagation of light & 5.76 & 9.23 \\
\hline 2 & Reflection of light & 6.18 & 9.32 \\
\hline 3 & $\begin{array}{l}\text { Interference - } \\
\text { Diffraction of light }\end{array}$ & 4.72 & 8.91 \\
\hline 4 & Refraction of light & 5.26 & 9.06 \\
\hline 5 & Absorption of light & 4.58 & 8.36 \\
\hline 6 & $\begin{array}{c}\text { Analysis - } \\
\text { Synthesis of light }\end{array}$ & 4.84 & 8.77 \\
\hline 7 & Polarization of light & 4.14 & 8.45 \\
\hline
\end{tabular}




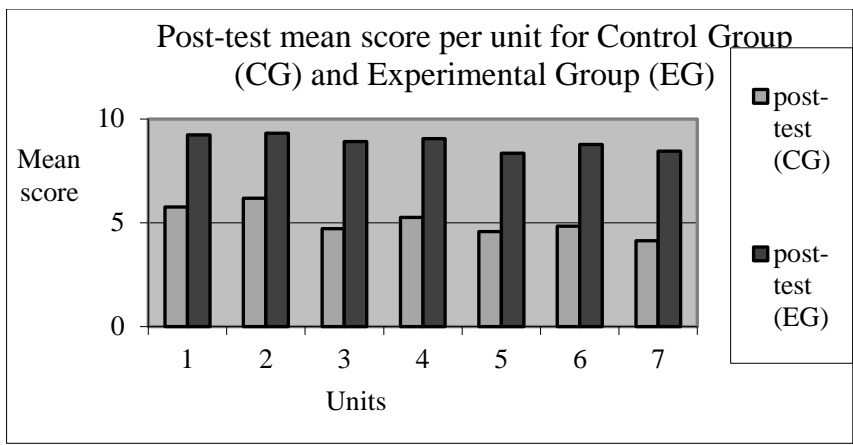

Fig. 1. Post-test mean score per unit for Control Group (CG) and Experimental Group (EG)

TABLE II: MEAN SCORE OF POST-TEST TOTAL AND FINAL-TEST FOR EXPERIMENTAL GROUP (EG)

\begin{tabular}{cccc}
\hline \hline Units & $\begin{array}{c}\text { Post-test } \\
\text { total }(\mathrm{CG})\end{array}$ & $\begin{array}{c}\text { Post-test } \\
\text { total (EG) }\end{array}$ & $\begin{array}{c}\text { Final-test } \\
(\mathrm{EG})\end{array}$ \\
\hline $1-7$ & 5.76 & 8.87 & 8.75 \\
\hline \hline
\end{tabular}

Comparison of post-test total for CG and EG and final test for EG

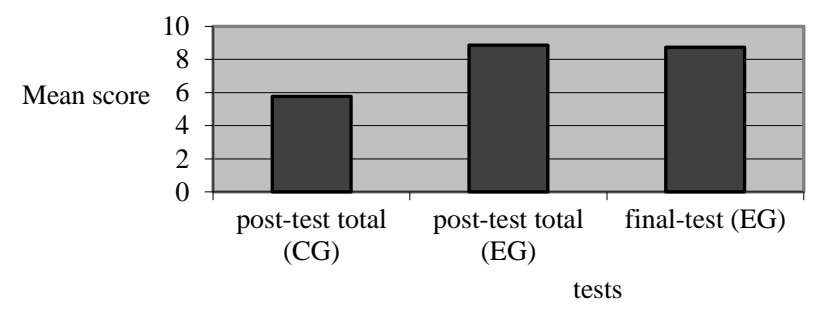

Fig. 2. Mean score for post-test total for Control Group(CG) and Experimental Group(EG) and final-test for Experimental Group (EG)

\section{A. Results per unit}

We present the statistics from the answers of post-test questions per unit mentioned that the highest score-excellent for every test is 10 . So the mean score for the post- test of every one of the seven units must be referred-compared to this score.

The last question $\left(10^{\text {th }}\right)$ of every test concerns the choice of the right-most appropriate model of light for the explanation-description of the phenomenon that studied in the unit.

Question: "Which model of light is the right model to explain - describe this phenomenon of light; a) both particles and waves, b) only the particle model, c) only the wave model, d) neither particles nor waves"

After teaching intervention, students gave correct answers in percentages in the range of $90 \%$ to $99 \%$ on the interpretation of phenomena using the most appropriate model.

The results of the learning intervention are very satisfactory, as the improvement in student responses are on average 3 to 4 degrees (scale of 10) in almost all questions.

Listed below summarizes comments and remarks on the data obtained in each subject.

\section{1) Propagation of light}

Mean score at post-test of Control Group (CG) 5.76 (standard deviation 1.26) and at post-test of Experimental Group (EG) 9.23 (standard deviation 0.74).
TABLE III: PROPAGATION OF LIGHT: PERCENTAGE OF CORRECT ANSWERS PER QUESTION IN POST-TEST OF CONTROL GROUP (CG) AND EXPERIMENTAL GROUP (EG)

\begin{tabular}{ccccccccccc}
\hline \hline & 1 & 2 & 3 & 4 & 5 & 6 & 7 & 8 & 9 & 10 \\
\hline CG & 60.0 & 56.0 & 70.0 & 54.0 & 58.0 & 52,0 & 56.0 & 62.0 & 50.0 & 58.0 \\
EG & 93.6 & 97.9 & 100.0 & 87.2 & 93.6 & 89.4 & 87.2 & 95.7 & 83.0 & 95.7 \\
\hline \hline
\end{tabular}

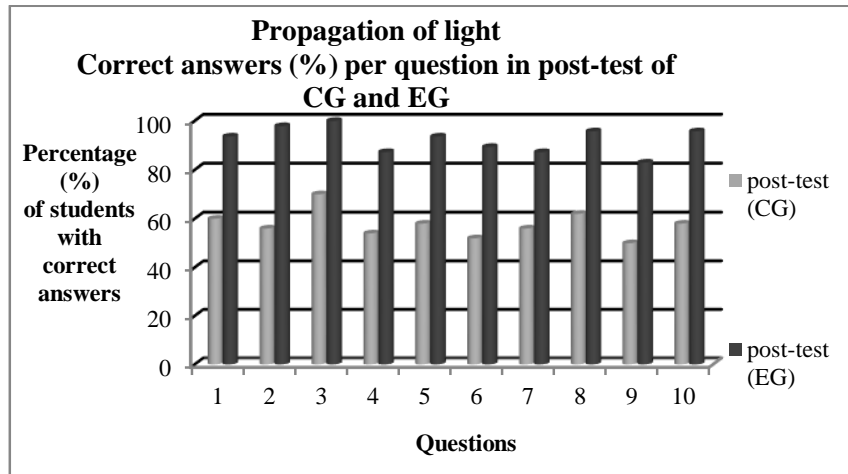

Fig. 3. Propagation of light: Percentage (\%) of correct answers per question in post-test of Control Group (CG) and Experimental Group (EG)

The $5^{\text {th }}$ question, for example is: "Shadow is a result of the: a) reflection of light, b) refraction of light, c) rectilinear propagation of light, d) absorption of light from the bodies"

\section{2) Reflection of light}

Mean score at post-test of Control Group (CG) 6.18 (standard deviation 1.42) and at post-test of Experimental Group (EG) 9.32 (standard deviation 0.83).

TABLE IV: REFLECTION OF LIGHT: PERCENTAGE OF CORRECT ANSWERS PER QUESTION IN POST-TEST OF CONTROL GROUP (CG) AND EXPERIMENTAL GROUP (EG)

\begin{tabular}{ccccccccccc}
\hline \hline & 1 & 2 & 3 & 4 & 5 & 6 & 7 & 8 & 9 & 10 \\
\hline CG & 64.0 & 82.0 & 76.0 & 28.0 & 62.0 & 60.0 & 70.0 & 78.0 & 26.0 & 72.0 \\
EG & 91.5 & 95.7 & 95.7 & 89.4 & 95.7 & 93.6 & 93.6 & 97.9 & 85.1 & 93.6 \\
\hline \hline
\end{tabular}

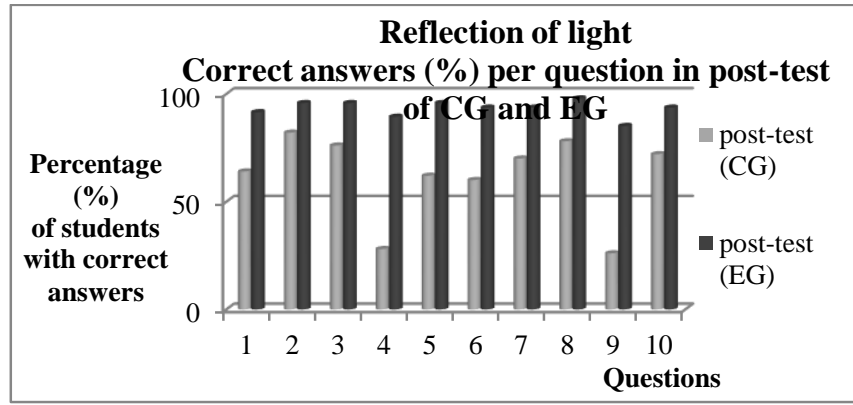

Fig. 4. Propagation of light: Percentage (\%) of correct answers per question in post-test of Control Group (CG) and Experimental Group (EG)

The $4^{\text {th }}$ question, for example is: "The phenomenon of reflection a) confined to electromagnetic waves detected by the human eye, b) does not apply to infrared and ultraviolet radiation, c) limited to radio waves, d) are common in all kinds of waves, electromagnetic and mechanical"

\section{3) Interference - Diffraction of light}

Mean score at pre-test 4.72 (standard deviation 1.81) and at post-test 8.91 (standard deviation 1.02).

TABLE V: INTERFERENCE - DIFFRACTION OF LIGHT

PERCENTAGE OF CORRECT ANSWERS PER QUESTION IN POST-TEST OF CONTROL GROUP (CG) AND EXPERIMENTAL GROUP (EG)

\begin{tabular}{ccccccccccc}
\hline & 1 & 2 & 3 & 4 & 5 & 6 & 7 & 8 & 9 & 10 \\
\hline CG & 74.0 & 72.0 & 48.0 & 52.0 & 32.0 & 36.0 & 40.0 & 34.0 & 32.0 & 52.0
\end{tabular}




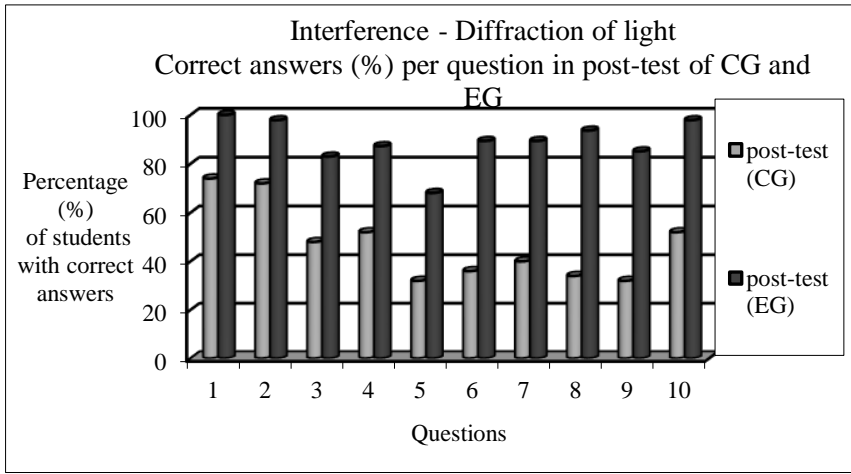

Fig. 5. Interference - Diffraction of light: Percentage (\%) of correct answers per question in post-test of Control Group (CG) and Experimental Group (EG)

The $5^{\text {th }}$ question, for example is: "Generally, diffraction occurs when light encounters a barrier or slit having dimensions relative to the wavelength of the propagating wave: a) much smaller, b) much larger, c) the same order of magnitude, d) either much smaller or much larger"

\section{4) Refraction of light}

Mean score at pre-test 5.26 (standard deviation 2.11) and at post-test 9.06(standard deviation 1.02).

TABLE VI: REFRACTION OF LIGHT: PERCENTAGE OF CORRECT ANSWERS PER QUESTION IN POST-TEST OF CONTROL GROUP (CG) AND EXPERIMENTAL GROUP (EG)

\begin{tabular}{ccccccccccc}
\hline \hline & 1 & 2 & 3 & 4 & 5 & 6 & 7 & 8 & 9 & 10 \\
\hline CG & 64.0 & 76.0 & 56.0 & 40.0 & 38.0 & 64.0 & 62.0 & 40.0 & 42.0 & 44.0 \\
EG & 97.9 & 100.0 & 89.4 & 76.6 & 78.7 & 91.5 & 95.7 & 93.6 & 89.4 & 93.6
\end{tabular}

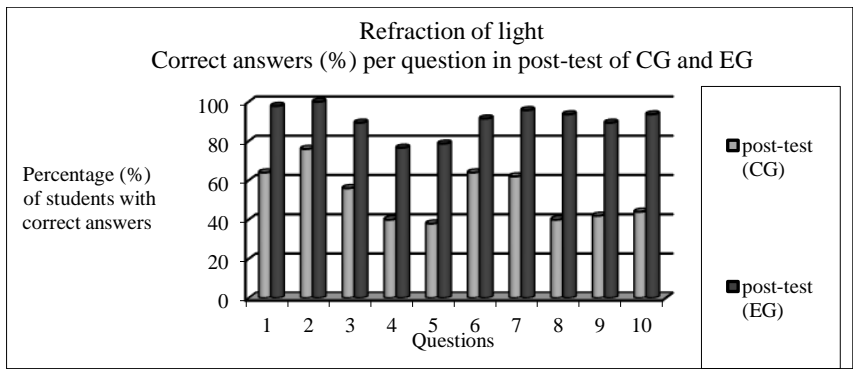

Fig. 6. Refraction of light: Percentage (\%) of correct answers per question in post-test of Control Group (CG) and Experimental Group (EG)

The $8^{\text {th }}$ question, for example is: "When one monochromatic light beam passes from one transparent medium into another with a different index of refraction, the angle of refraction, as compared with the angle of incidence is: a) less, b) the same, c) greater, d) may be any of the above"

\section{5) Absorption of light}

Mean score at pre-test 4.58 (standard deviation 1.81) and at post-test 8.36 (standard deviation 1.02).

TABLE VII: ABSORPTION OF LIGHT: PERCENTAGE OF CORRECT ANSWERS PER QUESTION IN POST-TEST OF CONTROL GROUP (CG) AND EXPERIMENTAL GROUP (EG)

\begin{tabular}{ccccccccccc}
\hline \hline & 1 & 2 & 3 & 4 & 5 & 6 & 7 & 8 & 9 & 10 \\
\hline CG & 46.0 & 76.0 & 48.0 & 50.0 & 32.0 & 42.0 & 48.0 & 42.0 & 30.0 & 44.0 \\
EG & 93.6 & 100.0 & 89.4 & 76.6 & 68.1 & 80.9 & 83.0 & 76.6 & 74.5 & 93.6
\end{tabular}

Absorption of light

Correct answers per question in post-test of CG and EG

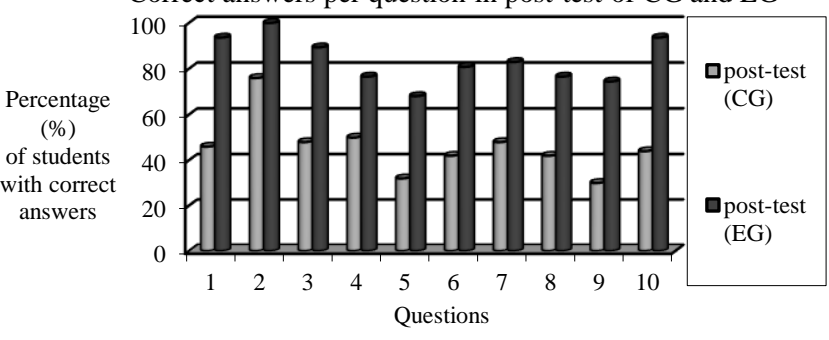

Fig. 7. Absorption of light: Percentage (\%) of correct answers per question in post-test of Control Group (CG) and Experimental Group (EG)

The $7^{\text {th }}$ question, for example is: "Photovoltaic shells: a) absorb all the solar energy that falls on them and convert it either into electricity or mechanical energy, or heat, b) absorb a part of light energy and convert it into heat c) absorb a part of light energy and convert it into electrical, d) absorb a part of light energy and convert it into mechanical"

6) Analysis - Synthesis of light

Mean score at pre-test 4.84 (standard deviation 1.81) and at post-test 8.77 (standard deviation 1.02).

TABLE VIII: ANALYSIS - SYNTHESIS OF LIGHT: PERCENTAGE OF CORRECT ANSWERS PER QUESTION IN POST-TEST OF CONTROL GROUP (CG) AND EXPERIMENTAL GROUP (EG)

\begin{tabular}{ccccccccccc}
\hline \hline & 1 & 2 & 3 & 4 & 5 & 6 & 7 & 8 & 9 & 10 \\
\hline CG & 76.0 & 72.0 & 42.0 & 54.0 & 42.0 & 38.0 & 36.0 & 56.0 & 34.0 & 34.0 \\
EG & 100.0 & 97.9 & 83.0 & 93.6 & 83.0 & 80.9 & 78.7 & 91.5 & 74.5 & 93.6
\end{tabular}

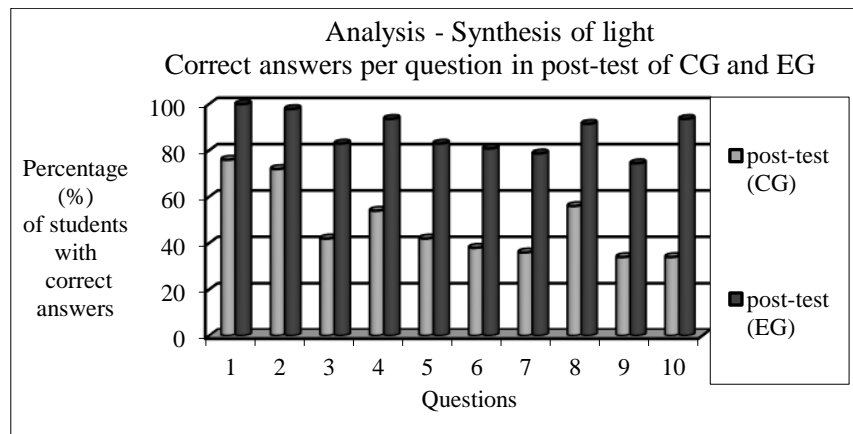

Fig. 8. Analysis - Synthesis of light: Percentage (\%) of correct answers per question in post-test of Control Group (CG) and Experimental Group (EG)

The $8^{\text {th }}$ question, for example is:"Rainbow: a) can be seen only when the sky there are water vapor, b) only appears at midday, c) only appears in the morning, d) all observers see the same at a given time."

\section{7) Polarization of light}

Mean score at pre-test 4.14 (standard deviation 1.31) and at post-test 8.45 (standard deviation 0.92 ).

TABLE IX: POLARIZATION OF LIGHT: PERCENTAGE OF CORRECT ANSWERS PER QUESTION IN POST-TEST OF CONTROL GROUP (CG) AND EXPERIMENTAL GROUP (EG)

\begin{tabular}{ccccccccccc}
\hline & 1 & 2 & 3 & 4 & 5 & 6 & 7 & 8 & 9 & 10 \\
\hline CG & 58.0 & 56.0 & 40.0 & 38.0 & 36.0 & 38.0 & 40.0 & 38.0 & 34.0 & 36.0 \\
EG & 97.9 & 93.6 & 83.0 & 80.9 & 80.9 & 78.7 & 78.7 & 87.2 & 74.5 & 89.4
\end{tabular}




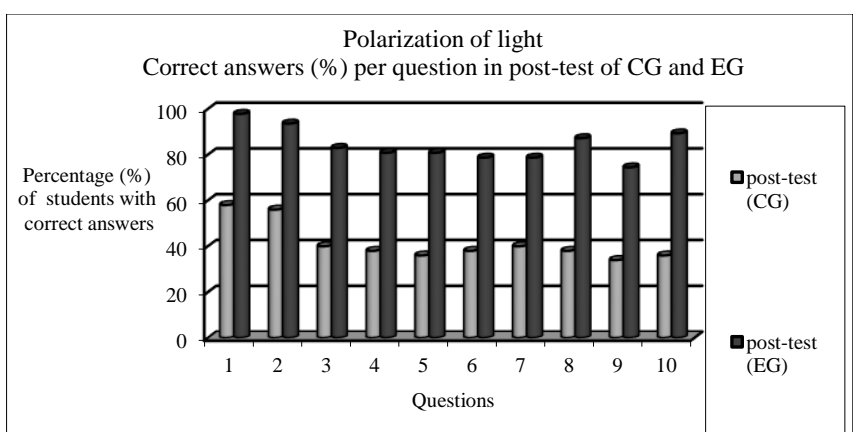

Fig. 9. Polarization of light: Percentage (\%) of correct answers per question in post-test of Control Group (CG) and Experimental Group (EG)

The $7^{\text {th }}$ question, for example is: "Our Polaroid glasses help to better see the snowy mountains and the sea because: a) "cut" UV, b) reduce the total amount of light that falls on the eyes, c) "cut" the infrared radiation, d). "chopping" the polarized component of the light from reflecting on snow or water."

\section{B. Comments on results per unit}

Students after teaching intervention perceive that light is waves and particles simultaneously. Also know that the photon is a particle with wave properties and that according to the electromagnetic theory light is waves, and according to quantum theory light is photons. Finally, they understand the cause of each phenomenon studied.

The results for the scores given for the implementation of a mixed teaching system (experiments in laboratory and software simulations) demonstrate that students are well predisposed towards it after their learning experience with the multimedia software. Students would like to have a methodology in their studies as a whole and they still value a teacher being present in the classroom however satisfactory their study has been using the interactive multimedia software.

At the end students complete a questionarie for the assesment of the educational application used as a teaching instrument (comparedwith the traditional on-site teaching).

\section{STUDENTS' INTERESTING COMMENTS FOR THE TEACHING METHOD}

The comments listed below were made by the students at the end of the series of seven exercises under completion, anonymous questionnaire of assessment - evaluation of educational procedure.

- The activities were interesting. There was no problem with the exercises. Everything was perfectly organized and meticulous. All showed interest.

- All things were made through a very pleasant atmosphere which is created and a positive attitude for the course.

- I think that optics experiments were more interesting than the corresponding software. The content of the activities, in the theoretical part, was perfectly understandable. I quite liked the visualizations.

- These activities were particularly interesting because they were mostly using software, which helped us to better understand the concepts learned. I think it is good all students to learn in this way.

- I think it was all very carefully structured. They helped me immensely in understanding the concepts, the applications often did at the laboratory bench.

- I think these seven exercises are especially important for our educational activity. The only item that might make them a bit tedious is the need to complete the brochures.

- It covered the most part of the issues with which we were dealing. Were fully understood the exercises and experiments. Highlights the most key points and concepts the teacher must know.

- It greatly helps to understand the syllabus. It especially facilitates better understanding of some phenomena through experiments.

- The process that we followed was very interesting, first theory and activities in computer and then experimenting on them.

- Good and targeted effort to introduce new technologies in the educational process.

- Some concepts that would be difficult to explain theoretically became easy to understand through the activities of the software.

- At that time, I took a tip about the wave-particle duality of light.

\section{CONCLUSIONS AND IMPLICATIONS}

One of the main goals of physics is to develop plausible conceptual models, as they are called, in terms of which various physical phenomena can be described and explained. Perhaps the outstanding example of this is the attempt to find a successful model for the phenomena of light. We know how people's ideas about the nature of light oscillated between a particle model and a wave model [8]. Light has properties that combine those of both particles and waves. Since there is no answer to the question: "Can there ever be a critical experiment that eliminates one theory and favours another?" we believe today that light has a dual nature. It is difficult to draw pictures or visualize this duality. As humans, we are restricted to thinking only about particles and waves independently. The research suggested that this is one of the biggest problem areas in the teaching of the topic.

The research suggested that light is a difficult topic to teach to students having no the appropriate background in mathematics and physics. After the new didactical approach - proposal, to upper secondary education students, the percentages of correct answers were over $85 \%$ (post-test) for most of the questions and this score was approximate the same one month later (final test).

There was surprisingly enough difference in degrees between post-tests of Control Group (CG) and Experimental Group (EG).

The innovative features of the educational intervention are:

- The transformation of scientific quantum standards to educational standards 
- The attempt to introduce the post-classical physics to secondary school students (high school) with the use of simulation and dynamic visualization of the microcosm (models of light).

- Teaching with a combination of software (computer) and classical experimental (laboratory)

- Promoting the integrating/coherent nature of science as accepted by modern theories and contributing to positive attitude towards physics.

Our didactical approach seems, from the assessment, to be quite encouraging and we suppose that it is appropriate not only for upper secondary students. We think that it will be beneficial and for non-major science university undergraduate students too.

This topic is chosen for upper secondary students, although it looks difficult for them as they don't have a strong mathematical background, because the current curriculum for the secondary physics education in Greece includes references to contemporary scientific theories.

In the same way, the physics of light should be taught by starting with the unified theory and showing that particle and wave theories are approximations to this and valid under certain definable conditions. When these conditions are met it is then acceptable to use a particle or wave approximation as appropriate.

It should be borne in mind that the study was carried out in a controlled environment and not in the normal on-site high-school teaching process. Although this could be seen as a limitation, it in fact reinforces the assessment results by introducing a greater degree of experimental rigour, as the avoidance of disrupting variables that might affect the conducting of the experiment was being sought (number of hours devoted to study, monitoring of teaching materials used in the research, etc.). The results obtained direct us to ways in which the research can be developed in the future.

\section{REFERENCES}

[1] R. V. Olsen, "Introducing quantum mechanics in the upper secondary school: a study in Norway", INT. J. SCI. EDUC., vol. 24, No. 6, 565574, 2002.

[2] S. Vokos, P.S. Shaffer, B.S. Ambrose and L.C. McDermott, "Student understanding of the wave nature of matter: Diffraction and interference of particles", Phys. Educ. Res., American Journal of Physics, Suppl. 68(7), , S42-S51, July 2000.

[3] I. Lawrence, "Quantum Physics In School", Physics Education, 31, No. 5 pp.278-286, September 1996.

[4] L. Deslauriers, C. Wieman C., "Learning and retention of quantum concepts with different teaching methods", Phys. Rev. ST Physics Ed. Research 7, 2011.

[5] H. Fischler H. and M. Lichtfeldt, "Modern physics and students' conceptions", International Journal of Science Education, 14 (2), pp.181-190, 1992.

[6] G. Ireson, G. "The quantum understanding of pre-university physics students", Physics Education, 35, 15-21, 2000.

[7] N. Voudoukis, "Application of Post - Classical Models of Light in Secondary and Higher Education through Experiments and Simulations - Design, Assessment and Proposals" Ph.D. dissertation, National University of Athens, Greece, 2013.

[8] A.P. French, Section B1, "The Nature of Physics" from: Connecting Research in Physics Education with Teacher Education, International Commission on Physics Education 1997,1998.

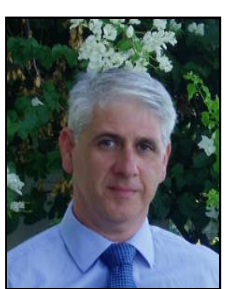

Nikolaos Voudoukis received a BSc degree in Physics from Athens National University, Greece, in 1991, a BSc in Electrical and Computer Engineering from the National Technical University of Athens, Greece, in 2012, his MSc degree in Electronics and Telecommunications from Athens National University, in 1993, and his $\mathrm{PhD}$ degree from Athens National University, in 2013. He has worked as telecommunication engineer in Greece, as teacher and Assistant Director at a high school and as a parttime Lecturer at the School of Pedagogical \& Technological. Education, Athens, Greece. Dr. Voudoukis now is with National Technical University of Athens, Greece. 